\title{
Managing Healthcare Budgets in Times of Austerity: The Role of Program Budgeting and Marginal Analysis
}

\author{
Craig Mitton · Francois Dionne - Cam Donaldson
}

Published online: 24 January 2014

(c) The Author(s) 2014. This article is published with open access at Springerlink.com

\begin{abstract}
Given limited resources, priority setting or choice making will remain a reality at all levels of publicly funded healthcare across countries for many years to come. The pressures may well be even more acute as the impact of the economic crisis of 2008 continues to play out but, even as economies begin to turn around, resources within healthcare will be limited, thus some form of rationing will be required. Over the last few decades, research on healthcare priority setting has focused on methods of implementation as well as on the development of approaches related to fairness and legitimacy and on more technical aspects of decision making including the use of multi-criteria decision analysis. Recently, research has led to better understanding of evaluating priority setting activity including defining 'success' and articulating key elements for high performance. This body of research, however, often goes untapped by those charged with making challenging decisions and as such, in line with prevailing public sector incentives, decisions are often reliant on
\end{abstract}

\section{Mitton}

University of British Columbia,

Vancouver, BC, Canada

C. Mitton · F. Dionne

Vancouver Coastal Research Institute,

Vancouver, BC, Canada

C. Mitton $(\bowtie)$

Centre for Clinical Epidemiology and Evaluation,

7th Floor, 828 West 10th Avenue Research Pavilion,

Vancouver, BC V5Z 1M9, Canada

e-mail: craig.mitton@ubc.ca

C. Donaldson

Glasgow Caledonian University,

Glasgow, UK historical allocation patterns and/or political negotiation. These archaic and ineffective approaches not only lead to poor decisions in terms of value for money but further do not reflect basic ethical conditions that can lead to fairness in the decision-making process. The purpose of this paper is to outline a comprehensive approach to priority setting and resource allocation that has been used in different contexts across countries. This will provide decision makers with a single point of access for a basic understanding of relevant tools when faced with having to make difficult decisions about what healthcare services to fund and what not to fund. The paper also addresses several key issues related to priority setting including how health technology assessments can be used, how performance can be improved at a practical level, and what ongoing resource management practice should look like. In terms of future research, one of the most important areas of priority setting that needs further attention is how best to engage public members. 


\section{Key Points for Decision Makers}

Program budgeting and marginal analysis (PBMA), multi-criteria decision analysis (MCDA), and accountability for reasonableness (A4R) are commonly used approaches for healthcare priority setting

These approaches can be used to improve the fairness and legitimacy of priority setting within healthcare organizations whilst ensuring that resources are allocated in the best manner possible

Health technology assessment is often viewed as a oneoff activity, whereas it should be seen as an input into a formal process for priority setting at the local or regional level

Key elements for high performance have been identified that can be used to improve priority setting practice in health service organizations

Examining investments and disinvestments, and thus opportunities for re-allocation, should be a part of an ongoing resource management strategy regardless of the external fiscal climate

\section{Introduction}

Public sector budgets have been under enormous pressure since the economic crisis of 2008 [1, 2]. So-called 'belt tightening' around the usual suspects of discretionary travel, consultant fees, and overtime expenditure typically garner the expected first wave of attention. While this may be palatable politically, in reality such cost savings barely scratch the surface, in part because many healthcare organizations have been 'leaning up' for well over a decade. Of course it is not to say that there are no efficiency gains that can be made, but it would be atypical to identify a plethora of low-hanging fruit in this day and age.

Acknowledging this, researchers and policy makers have turned attention to pulling resources from areas of ineffective care. For example, in the UK, the National Institute for Health and Clinical Excellence has been producing 'do not do' lists for a number of years now [3]. Furthermore, work in Australia has identified over 150 areas of care that health service delivery organizations could potentially stop doing based on the latest evidence [4]. The important point is that it is clear that there are tangible service areas from which resources should be released, thereby freeing resources to go towards government bottom lines or for re-investment elsewhere in the system. The question then becomes, are even more resources required to be 'found' beyond efficiency gains and stopping ineffective services?

The answer to this question will depend on the context. In some relatively cash-rich systems where the notion of scarcity has not come to the fore, indeed the impetus to 'go further' may simply not be there. However, in most countries today, following the current extended economic downturn and limited hope for a near-term recovery, there is really only one option. Decision makers must look at releasing resources from areas of care that are in fact producing some benefit [5]. This clearly is no easy task, as those in charge of the system would need to stare down their political paymasters and stand firm in saying that to fund more of some things resources will have to be taken from existing lower value yet still benefit-producing services.

While no doubt a daunting task, there are tools in the healthcare manager's toolbox that can assist. This short paper focuses on several of these tools including program budgeting and marginal analysis (or PBMA), and along with it, a common method for benefit measurement known as multi-criteria decision analysis (MCDA). While PBMA hails from health economics and has as its central tenet the notion of value for money, the literature also points to the need to ensure that the decision-making process itself is viewed as fair and legitimate. Thus, there is a need to also draw on other disciplines such as ethics in developing what might be called a 'comprehensive approach' to healthcare priority setting [6].

While some of the concepts contained in this paper are not new in and of themselves, this paper is relevant as decision makers continue to have a lack of awareness and fulsome understanding of the tools available to them. In the next section, a comprehensive approach to priority setting and resource allocation for healthcare organizations is outlined including some advantages and potential weaknesses. Following this, a number of key issues are addressed including the link between health technology assessment and priority setting at the local or regional level, how organizations can go about improving their priority setting activity in practical terms, and finally why it is critical that proactive methods for priority setting are required not just in times of serious fiscal constraint. The paper closes with some thoughts on where to now for the field of healthcare priority setting. The purpose of this paper is to outline good management practice for decision makers based on what is known in the literature and drawing from our own experience on priority setting and resource allocation processes with over 50 organizations across multiple countries.

\section{Comprehensive Approach}

Program budgeting and marginal analysis is an approach to priority setting that has been around for over 30 years and 
has been applied over 150 times in health service organizations across a number of countries [7-11]. The approach is based on two fundamental economic concepts, opportunity cost and the margin. Opportunity cost is the benefit forgone by not investing in the next best use of resources; the implication of which is that costs and benefits of service options need to be assessed on an ongoing basis. However, because of the second principle of the margin, which refers to benefit gain (or loss) associated with the next unit of resources, not every funding decision requires a full costbenefit analysis. That is, changes for increased funding and decreased funding can be assessed relative to existing practice. This alleviates the need to compare all programs and services from the bottom up (i.e., with a zero-based budgeting approach); instead, managers and clinical leaders can propose changes at the margin that will incur the least harm (in the case of decreased funding) or achieve the most benefit (in the case of increased funding) when measured against a given set of objectives. Note also that 'margin' here does not mean 'marginal' or 'small'; changes at the margin can indeed be very large, but need to be thought of as a step up (or down) in service provision and the benefit gain (or loss) associated with that step. The challenge of course is that forgone benefit is often not explicitly measured and while program evaluations are common, thinking at the margin is much less prevalent. As a result, organizations are not allocating resources in the best manner possible and will often rely on political and/or historical allocation approaches [12]. PBMA has seven steps (see Table 1) and allows an organization to become more systematic in its approach to priority setting and resource allocation [13].

One question that often arises is how should the concept of benefit be measured? For example, if an organization comes up with a list of possible disinvestment options (i.e., areas for service reduction), what methods are available for comparing these options, in terms of relative value, against options for investment? One approach that is gaining momentum in healthcare, but which has been around in other sectors for many decades, is MCDA [14]. Again referring to Table 1, MCDA can be used in step 5 for determining the level of benefit associated with the proposals for change (i.e., marginal proposals) under consideration. In its simplest form, MCDA involves identifying a set of evaluation criteria and then rating each service option against each criterion to come up with a 'benefit score' reflecting the level of benefit associated with the given proposal [15]. Using a symmetric negative-to-positive rating scale, options for investment and disinvestment can be compared directly [16]. As health service organizations have multiple objectives, and thus multiple criteria, clinicians and managers often view MCDA favorably.

Another framework found in the priority setting literature is accountability for reasonableness (A4R). A4R serves as an important moral guide for decision makers in ensuring that their priority setting process is fair and legitimate. The framework espouses five conditions upon which any process should follow (see Table 2) [17, 18]. In essence, good practice from an ethical point of view would involve using explicit criteria in assessing options, basing

Table 1 Program budgeting and marginal analysis (PBMA) steps (see Ref. [13])

1. Determine the aim and scope of the priority setting exercise

Determine whether PBMA will be used to examine changes in services within a given program or between programs; identify in and out of scope programs.

2. Compile a "program budget"

The resources and costs of programs may need to be identified and quantified, which, when combined with activity information, comprises the program budget.

3. Form a "marginal analysis" advisory panel

The panel is made up of key stakeholders (managers, clinicians, consumers etc.) in the priority setting process.

\section{Determine locally relevant decision-making criteria}

To be elicited from the advisory panel (e.g. maximising benefits, improving access and equity, reducing waiting times etc.), with reference to national, regional and local objectives, and specified objectives of the health system and the community.

5. Identify options for (a) service growth (b) resource release from gains in operational efficiency (c) resource release from scaling back or ceasing some services

The program budget, along with information on decision-making objectives, evidence on benefits from service, changes in local health care needs, and policy guidance, are used highlight options for investment and disinvestment.

\section{Evaluate investments and disinvestments}

Evaluate in terms of costs and benefits and make recommendations for (a) funding growth areas with new resources (b) moving resources from 5 (b) and 5 (c) to 5 (a).

\section{Validate results and reallocate resources}

Re-examine and validate evidence and judgements used in the process and reallocate resources according to cost-benefit ratios and other decision-making criteria. 
Table 2 Accountability for Reasonableness conditions
Relevance
Decisions based on reasons fair-minded people can agree are relevant under the circumstances
Publicity Reasons publicly accessible
Revision Opportunities to revisit/revise decisions and mechanism to resolve disputes
Empowerment Power differences minimized and effective participation optimized
Enforcement Mechanisms to ensure above 4 conditions met

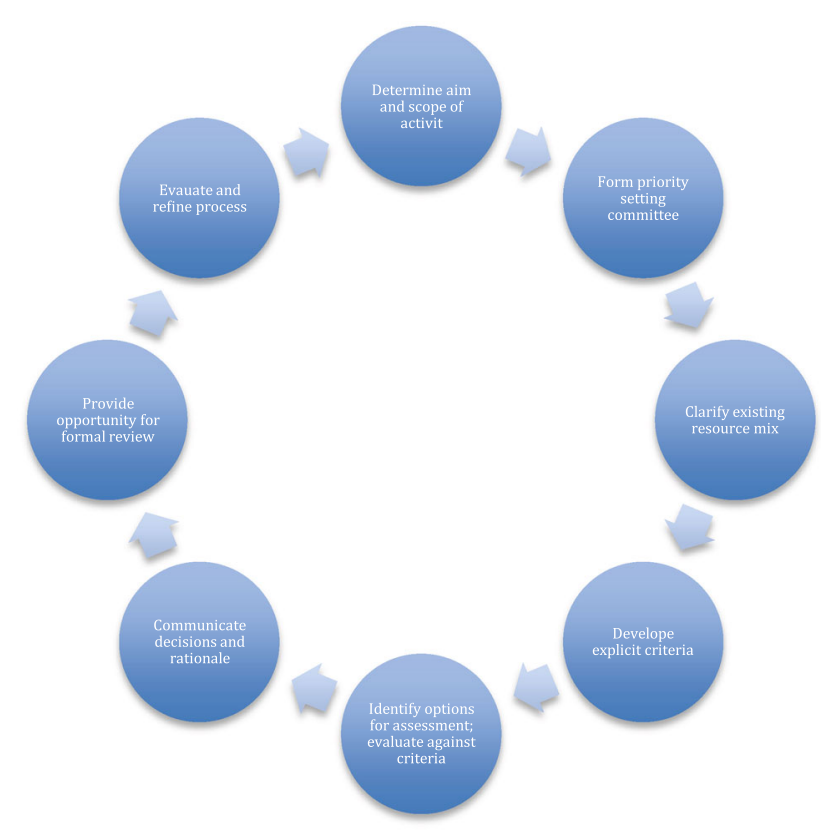

Fig. 1 Comprehensive approach to priority setting (adapted from Ref. [19])

decisions on the best evidence possible, minimizing power imbalances, including a decision review or appeals process, and making sure the priority setting approach is as transparent as possible. Over the last few years, researchers have made efforts to design a 'comprehensive approach' to priority setting, which draws on the basic steps of PBMA (including use of MCDA), while at the same time ensuring the ethical conditions underlying A4R are adhered to [6, 19] (see Fig. 1). For example, transparency (i.e., publicity condition) has been shown to be a key element of fair process [19], so ensuring that the process itself is communicated along with the specific criteria being used, and then further, clearly describing what decisions have been made as well as the rationale for those decisions (step 6), all become part of the steps for good practice in operationalizing Fig. 1. Further, having explicit criteria (step 4) and using available evidence in the assessment of proposals for investment and disinvestment (step 5) serves to meet the relevance condition. This serves to focus decision makers on both value for money in their decisions as well as fair process in coming up with those decisions. The revision condition is met through step 7 , and empowerment is addressed in discussions around assessment of the proposals (step 5). Both the literature and experience clearly indicate that considering elements of fairness at the outset will mitigate challenges throughout the priority setting process.

On paper these methods likely will make some sense and while acknowledging the complexities of modern health service organizations, the priority setting methods per se are relatively straightforward. Over the last decade, numerous surveys have been conducted with decision makers that have used these approaches. Respondents have indicated that not only is there value in moving or shifting resources in a fair manner to achieve greater benefit, but also have indicated advantages such as greater ownership of decisions and greater levels of engagement of clinicians and other key stakeholders [12, 20, 21]. That said, potential weaknesses may include the time and data requirements to carry out this work [5]. However, decision makers are often devoting some time to priority setting as is, so incrementally the draw on resources may not be that large, particularly once a new process is in place. Further, in terms of data, while it is true that the approaches do not produce data per se, often organizing the available data in a more rigorous manner can be useful, and at the very least can point to gaps where local data collection would contribute to better decision making. There may also be challenges with coming to agreement on what a 'fair process' looks like. For example, there may be disagreement on appropriate levels of evidence or who is best suited in a given context to provide 'reasoned' assessment; however, seeking to follow the normative conditions outlined in Table 2 have been shown many times across contexts and countries to lead to fairer, more legitimate process [6, 18].

Overall, the messages here are simple: first, there are approaches available to support decision makers in setting priorities and allocating resources. Second, these approaches are not context specific in that they are applicable in any organization or system where choices have to be made about what to fund and what not to fund. Third, instead of viewing economics and ethics as competing disciplines, it may be useful to think about drawing on both economics and ethics in devising a comprehensive approach to priority setting. Finally, the vast majority of decision makers including clinicians who have applied these approaches in 
practice indicate that they would not want to go back to historical allocation or political negotiation as the predominant forms used for priority setting in their organization $[5,12,21]$.

\section{Key Issues}

This section highlights a number of key issues that in our view have not been satisfactorily dealt with in the literature and with which decision makers continue to face significant challenges in the implementation of their priority setting activity. That said, the intention is to present issues but not dive deeply here; readers are referred to references provided as a starting point for further investigation.

\subsection{HTA and Priority Setting}

Over the last two decades there have been substantial efforts by health technology assessment (HTA) agencies in conducting evidence-based reviews on new services and technologies [22]. In some cases, such reviews have used a formal MCDA process, which is important as decision makers have to make decisions not only on clinical and cost effectiveness but a broader set of criteria as well, as discussed above [23]. However, the link that has not been made clearly in the literature is that HTA activity should feed directly into a formal approach for priority setting at the local or regional level. For example, an executive team of a regional health board might review the relevant evidence of a given new technology from an HTA report produced by a national agency. What the report is unable to do, however, is to inform that executive team of the opportunity cost of implementation in their specific context and thus in and of itself that report cannot provide a reliable recommendation for action. In contrast, if the executive team had a formal priority setting approach in place, they could review the HTA report in light of the other calls for funding across their region and assess the relative value of the new technology vis-à-vis existing services and other investment opportunities. The HTA report then necessarily should speak to a broad set of decision criteria and second should not include a recommendation for action at the local or regional level.

\subsection{Improving Performance Practically}

Recent work in Canada has identified a set of key elements for high performance in priority setting implementation. This work builds on previous activity in the UK on World Class Commissioning [24] as well as other work from Canada and elsewhere on defining and measuring 'success' in priority setting $[25,26]$. The research team conducted a national survey of health authority executives and then carried out in-depth case studies of six geographically dispersed organizations from across Canada to first determine what high performance is with respect to priority setting practice and then determine key elements that help describe this construct for decision makers. In defining a set of key elements (highlights outlined in Table 3), organizations can then assess their current practices and determine areas for improvement based on evidence for best practice. The most basic notion to draw from Table 3 is simply to have a process in place. This may seem completely intuitive but yet many organizations in Canada, and likely elsewhere, still do not have a formal, organization-wide process for priority setting in place [27]. In addition, one of the key elements often overlooked in health service organizations is the need to engage staff (including clinicians) as well as members of the public in priority setting implementation. Importantly, new tools including proprietary software packages such as Prioritize Software (http://www.prioritizesoftware.com) from Canada and 1000 Minds (http://www.1000minds.com/) from New Zealand are available to assist decision makers in the implementation of a formal process for priority setting and specifically in improving key aspects of the process such as staff and clinician engagement.

\subsection{Fiscal Constraints}

One concern with the current fiscal crisis is that it will at some point come to an end. Why could this possibly be a concern? The pattern in most health systems is that cuts are made when resources are scarce and then when surpluses arrive funds are allocated with less scrutiny. What is required is sound resource management regardless of the fiscal climate. To get away from the chaotic spend vs. slash cycle, a number of practical solutions can be put in place. First, in times of surplus, contingency funding should be accumulated as a matter of course to help mitigate the impact on the public sector during economic downturns. Second, the same level of accountability should be maintained in both deficit and surplus conditions so that the relative value of investments and disinvestments are assessed routinely. The key is determining where resources can be released from within a given budget even if more money is coming into the system. Finally, no single part of an organization should be given a 'pass'. That is, every part of the health service should be required to propose lowvalue options and then the process, using for example an MCDA approach, can determine from where resources should be released based on relative merit. A priori 'out of scope' decisions can compromise process transparency and legitimacy and thus full scope is almost always preferable. 
Table 3 Summary of elements of high performance

\begin{tabular}{|c|c|c|c|}
\hline Structure & Processes & Attitudes/behaviours & Outcomes \\
\hline $\begin{array}{l}\text { SMT has the ability and authority to } \\
\text { move financial resources within } \\
\text { and across silos }\end{array}$ & $\begin{array}{l}\text { PSRA at the organization-wide } \\
\text { level is based on economic and } \\
\text { ethical principles and involves: } \\
\text { - Well-defined, weighted criteria } \\
\text { which reflect the organization's } \\
\text { values and strategic priorities } \\
\text { - Use of a scoring tool to } \\
\text { operationalize criteria in ranking } \\
\text { individual proposals } \\
\text { - Mechanisms for incorporating } \\
\text { best available evidence } \\
\text { - A decision review mechanism }\end{array}$ & $\begin{array}{l}\text { Fit of priority setting decisions with } \\
\text { social and community values is } \\
\text { sought: } \\
\text { - Public participation and input is } \\
\text { valued; it is integrated into } \\
\text { decisions in meaningful ways. } \\
\text { - Consideration is given to how } \\
\text { decisions align with external } \\
\text { partners and the larger health } \\
\text { system. }\end{array}$ & $\begin{array}{l}\text { Actual reallocation of } \\
\text { financial resources is } \\
\text { achieved }\end{array}$ \\
\hline $\begin{array}{l}\text { Mechanisms are established for } \\
\text { engagement of staff (clinical and } \\
\text { non-clinical) in PSRA decisions, } \\
\text { with particular though not } \\
\text { exclusive attention to physicians } \\
\text { - May include the use of incentives } \\
\text { to encourage participation }\end{array}$ & $\begin{array}{l}\text { SMT ensures effective } \\
\text { communication (both internally } \\
\text { and externally) around its } \\
\text { priority setting and resource } \\
\text { allocation-leading to } \\
\text { transparency }\end{array}$ & $\begin{array}{l}\text { SMT displays strong leadership for } \\
\text { PSRA-SMT is aware of and } \\
\text { manages the external environment } \\
\text { and other constraining factors, and } \\
\text { is willing to take and stand behind } \\
\text { tough decisions. }\end{array}$ & $\begin{array}{l}\text { Resource allocation } \\
\text { decisions are justified in } \\
\text { light of the organization's } \\
\text { established and agreed } \\
\text { upon core values. }\end{array}$ \\
\hline
\end{tabular}

SMT senior management team, PSRA priority setting and resource allocation

\section{Discussion}

This paper has outlined a comprehensive approach to healthcare priority setting that draws on the underlying disciplines of economics and ethics. The approach can be applied regardless of the fiscal climate and in fact in our view there is some danger of returning to budget surpluses, as the primary external impetus for prudent resource management will disappear. The contribution of this paper has been in reviewing concepts that have been around for many years but have not been adequately recognized or are not well enough understood to be applied in practice. Other papers provide a more detailed, comparative review of a broader set of tools in the priority setting toolbox [28]. Furthermore, in addressing a number of key issues related to priority setting, our intent was to stimulate new thinking on these matters and importantly assist decision makers in practical terms.

The basic point that decision makers, politicians, and perhaps most importantly the public need to understand is that even when the economy is growing and healthcare is receiving higher year-on-year rates of growth, the concept of shifting or re-allocating resources from lower to higher value program areas is essential. While this might sound like a particularly private sector way of thinking, in fact any budget held by a given public or private sector organization must re-allocate resources in an ongoing manner to get the most out of its limited pot of resources. This will mean that there are winners and losers and understandably this is, at least on one level, extremely difficult. However, when the principle of opportunity cost is properly understood, it is actually unfair and inequitable not to evoke winners and losers when managing limited resources.

Many gains have been made over the last few decades in the field of healthcare priority setting, yet as one example in Canada, still only $50 \%$ of health service delivery organizations profess to having a formal approach to priority setting and resource allocation in play at the organizational level [27]. The key question then becomes why has uptake been so challenging, as it is not as if the approaches described herein are overly complex in and of themselves.

Like many fields in medicine, more work certainly needs to be done on knowledge translation, so that what is known can be applied to impact real-world decision processes. However, looking beyond dissemination, one would be remiss not to point to incentives as a key barrier to adoption [5]. In many contexts, incentives are misaligned between physicians as drivers of service use and health regions seeking to constrain costs, and when these two key actors are not proactively working together it is extremely difficult for a unified approach to priority setting to be taken up. Furthermore, public sector bureaucracies have built-in incentives that mitigate the use of a formal approach to priority setting, in that such approaches do take time and additional effort, yet individual administrators are often not rewarded for their performance with respect to how efficient they are managing a budget. Thus, one key area for additional work in this field is for researchers to work with senior executives and health ministries to examine how incentives might be introduced to overcome 
challenges to adoption of explicit, systematic approaches to priority setting.

Other areas that require more attention going forward, in line with work from Australia and the UK on ineffective services [29], would be in establishing inventories of changes at the margin that could be used as idea generators within a given context. Finally, there is still only a handful of examples whereby public engagement with respect to healthcare priority setting has been done well [30]. Much more work is needed in this specific area to identify efficient and effective mechanisms for appropriate and meaningful input from members of the public.

\section{Conclusion}

For the decision maker faced with having to make difficult choices amongst competing claims on limited resources, some solace can be found in knowing that there is a substantial literature on healthcare priority setting and that there are readily available and adaptable tools to assist in this activity. Of course, moving from knowing to doing and getting the implementation right is one of the most challenging aspects of healthcare decision making [31], but again, practically speaking, the available tools are not complex in and of themselves. With strong leadership and project management, many organizations have implemented the approaches discussed in this paper with high degrees of success [32]. Not only can resources be shifted in a more explicit and rigorous manner, but also managers and clinicians alike, and even public members, can be appropriately engaged, thereby inherently improving what will always be a values-laden activity. In short, moving away from political negotiation and historical patterns of allocation to assess opportunity cost and release resources from within to fund investment proposals will lead to better use of healthcare resources. While this may not be as attractive as the latest politically initiated system reform, it will in actuality lead to better value and, ultimately, health system sustainability.

Funding and conflicts of interest No external funding was received for this paper.

The authors are partners in the Prioritize Software enterprise mentioned in the text. No other perceived or real conflicts exist.

\footnotetext{
Author contributions This paper was conceived by CM upon invitation to write an update on use of PBMA from the Editor of Applied Health Economics and Health Policy. Major contributions to the "Comprehensive approach" and "Key issues" sections, in particular, were made by CD and FD. CM is the guarantor for the overall content.
}

Open Access This article is distributed under the terms of the Creative Commons Attribution Noncommercial License which permits any noncommercial use, distribution, and reproduction in any medium, provided the original author(s) and the source are credited.

\section{References}

1. Appleby J, Crawford R, Emmerson C. How cold will it be? Prospects for NHS funding: 2011-17. The King's Fund \& Institute for Fiscal Studies; 2009.

2. Callan T, Nolan B, Walsh J. The economic crisis, public sector pay and the income distribution. Germany (Bonn): Institute for the Study of Labor; 2010.

3. Pearson S, Littlejohns P. Reallocating resources: how should the National Institute for Health and Clinical Excellence guide disinvestment efforts in the National Health Service? J Health Serv Res Policy. 2007;12(3):160-5.

4. Elshaug AG, Moss JR, Littlejohns P, Karnon J, Merlin TL, Hiller JE. Identifying existing health care services that do not provide value for money. Med J Aust. 2009;5(2):269-73.

5. Mitton C, Donaldson C. The priority setting toolkit: a guide to the use of economics in health care decision making. London: BMJ Books; 2004.

6. Gibson JL, Mitton C, Martin DK, Donaldson C, Singer PA. Ethics \& economics: does program budgeting and marginal analysis contribute to fair priority setting? J Health Serv Res Policy. 2006;11(1):32-7.

7. Cohen D. Messages from Mid Glamorgan: a multi-programme experiment with marginal analysis. Health Policy. 1995;33:147-55.

8. Astley J, Wake-Dyster W. Evidence-based priority setting. Aust Health Rev. 2001;24(2):32-9.

9. Viney R, Haas M, De Abreu Lourenco R. A practical approach to planning health services: using PBMA. Aust Health Rev. 2000;23(3):10-9.

10. Mitton C, Patten S, Waldner H, Donaldson C. Priority setting in health authorities: a novel approach to a historical activity. Soc Sci Med. 2003;57:1653-63.

11. Dionne F, Mitton C, Smith N, Donaldson C. Evaluation of the impact of program budgeting and marginal analysis in Vancouver Island Health Authority. J Health Serv Res Policy. 2009;14(4): 234-42.

12. Bate A, Donaldson C, Murtagh MJ. Managing to manage healthcare resources in the English NHS? What can health economics teach? What can health economics learn? Health Policy. 2007;84(2-3):249-61.

13. Peacock S, Ruta D, Mitton C, Donaldson C, Bate A, Murtagh M. Using economics for pragmatic and ethical priority setting: two checklists for doctors and managers. BMJ. 2006;332:482-5.

14. Baltussen R, Niessen L. Priority setting of health interventions: the need for multi-criteria decision analysis. Cost Eff Res Allocation. 2006;4:14.

15. Wilson EC, Peacock SJ, Ruta D. Priority setting in practice: what is the best way to compare costs and benefits? Health Econ. 2009;18(4):467-78.

16. Wilson E, Sussex J, Macleod C, Fordham R. Prioritizing health technologies in a primary care trust. J Health Serv Res Policy. 2007;12(2):80-5.

17. Daniels N, Sabin J. Setting limits fairly: can we learn to share medical resources?. Oxford: Oxford University Press; 2002.

18. Gibson JL, Martin DK, Singer PA. Setting priorities in health care organizations: criteria, processes and parameters of success. BMC Health Serv Res. 2004;4:25.

19. Gibson J, Mitton C, Dubois-Wing G. Priority setting in Ontario's LHINs: ethics and economics in action. Health Care Quat. 2011;14(4):35-46.

20. Teng F, Mitton C, MacKenzie J. Priority setting in the Provincial Health Services Authority: survey of key decision makers. BMC Health Serv Res. 2007;7:84.

21. Mitton C, Donaldson C. Setting priorities and allocating resources in health regions: lessons from a project evaluating program 
budgeting and marginal analysis (PBMA). Health Policy. 2003;64:335-48.

22. Ibargoyen-Roteta N, Gutierrez-Ibarluzea I, Asua J. Guiding the process of health technology disinvestment. Health Policy. 2010;98:218-26.

23. Husereau D, Boucher M, Nourani H. Priority setting for health technology assessment at CADTH. Int J Technol Assess Health Care. 2010;26:341-7.

24. McCafferty S, Williams I, Hunter D, Robinson S, Donaldson C, Bate A. Implementing world class commissioning competencies. J Health Serv Res Policy. 2012;17(Suppl 1):40-8.

25. Sibbald SL, Singer PA, Upshur R, Martin DK. Priority setting: what constitutes success? A conceptual framework for successful priority setting. BMC Health Serv Res. 2009;9:45. doi:10.1186/ 1472-6963-9-43.

26. Kapiriri L, Martin DK. Successful priority setting in low and middle income countries: a framework for evaluation. Health Care Anal. 2010;18(2):129-47.
27. Smith N, Mitton C, Bryan S, Davidson A, Urquhart B, Gibson J, Peacock S, Donaldson C. Decision maker perceptions of resource allocation processes in Canadian Health Care Organizations: a national survey. BMC Health Serv Res. 2013;13:247.

28. Mitton C, Donaldson C. Tools of the trade: a comparative analysis of approaches to priority setting in health care. Health Serv Manag Res. 2003;16:96-105.

29. Elshaug AG, McWilliams JM, Landon BE. The value of lowvalue lists. JAMA. 2013;309(8):775-6.

30. Mitton C, Smith N, Peacock S, Evoy B, Abelson J. Public participation in health care priority setting: a scoping review. Health Policy. 2009;91(3):219-29.

31. Williams I, Robinson S, Dickinson H. Rationing in health care: the theory and practice of priority setting. Bristol: Policy Press; 2012.

32. Tsourapas A, Frew E. Evaluating 'success' in programme budgeting and marginal analysis: a literature review. J Health Serv Res Policy. 2011;16(3):177-83. 